\title{
Significado atribuído por trabalhadores da saúde de Belo Horizonte-MG ao princípio da resolutividade nas ações cotidianas
}

\author{
Meaning given by health workers of Belo Horizonte-MG to the principle of resolvability in everyday actions \\ Significado atribuido por trabajadores de salud de Belo Horizonte-MG al principio de \\ resolubilidad en las acciones cotidianas
}

\section{Lilian Machado Torres', Lorena Márcia de Freitas Marques', Meire Chucre Tannure', Claudia Maria Mattos Penna"}

\author{
' Universidade Federal de Minas Gerais, Escola de Enfermagem, Programa de Pós-Graduação em Enfermagem \\ (Doutoranda). Belo Horizonte-MG, Brasil. \\ "Universidade Federal de Minas Gerais, Escola de Enfermagem, Programa de Pós-Graduação em Enfermagem. \\ Belo Horizonte-MG, Brasil.
}

Submissão: 03-05-2011 Aprovação: 13-11-2012

\section{RESUMO}

Trata-se de estudo qualitativo, fundamentado na sociologia compreensiva, cujo objetivo foi o de compreender o significado atribuído pelos profissionais da rede hierarquizada de saúde de Belo Horizonte-MG, Brasil, ao princípio da resolutividade nas ações cotidianas de saúde. Trinta e dois trabalhadores foram os informantes desta pesquisa. Foi utilizada a entrevista semiestruturada e a técnica de análise de conteúdo. Profissionais descrevem o que é resolutividade e fatores que dificultam sua concretização. Percebem, também, que os pacientes nem sempre saem das Unidades com a resposta que desejam; e que o serviço é resolutivo no que corresponde ao seu nível de atenção, embora para a população e alguns gerentes seja o inverso. Conclui-se que se torna premente a reorganização de aspectos relacionados a este princípio doutrinário do SUS.

Descritores: Sistema Único de Saúde; Saúde Coletiva; Acesso Universal a Serviços de Saúde; Assistência à Saúde.

ABSTRACT
This is a qualitative study, based on comprehensive sociology, which aimed to understand the meaning assigned by health professionals of Belo Horizonte-MG, Brazil, to the principle of resolvability in the everyday actions of health. Thirty-two workers were the informants of this research. We used a semi-structured interview technique and content analysis. Professionals describe what is the solution and the factors that hinder their achievement. They realize, too, that patients do not always leave the Units with the response they want; and that the service is resolute in that matches your level of attention, although for some people and managers is the reverse. We conclude that it becomes urgent to reorganize aspects of this doctrinal principle of SUS.

Key words: Unified Health System; Public Health; Universal Access To Health Care Services; Delivery of Health Care.

\section{RESUMEN}

Se trata de un estudio cualitativo, basado en la sociología comprensiva, cuyo objetivo fue comprender el significado atribuido por profesionales de la salud de la red de salud de Belo Horizonte-MG, Brasil, al principio de resolubilidad en las acciones cotidianas de salud. Treinta y dos trabajadores fueron los informantes de esta investigación. Se utilizó una técnica de entrevista semi-estructurada y el análisis de contenido. Los profesionales describen lo que es resolubilidad y los factores que dificultan su logro. Dan cuenta, también, que los pacientes no siempre salen de las Unidades con la respuesta que ellos quieren; y que el servicio es resolutivo en lo que corresponde a su nivel de atención, aunque para algunas personas y gerentes sea lo inverso. Concluye-se que se hace urgente reorganizar los aspectos de este principio doctrinal del SUS.

Palabras clave: Sistema Único de Salud; Salud Pública; Acceso Universal a Servicios de Salud; Prestación de Atención de Salud. 


\section{INTRODUÇÃO}

O Sistema Único de Saúde (SUS) instituído com a promulgação da Constituição Brasileira de 1988 é baseado na assertiva da saúde como direito de todos e dever do estado. Ele é considerado atualmente um dos maiores sistemas públicos de saúde do mundo e é chamado de sistema único porque segue os mesmos princípios em todo o território nacional, sob a responsabilidade dos governos federal, estadual e municipal, tendo como objetivo comum atividades de promoção, proteção e recuperação da saúde ${ }^{(1)}$.

Atualmente, o SUS atinge todo o país, graças ao processo de municipalização, que transferiu recursos e responsabilidades das esferas federal e estadual diretamente aos municípios ${ }^{(2)}$.

Com a criação do SUS surge um conceito de saúde mais amplo, no qual a saúde passa a ser considerada como um componente da qualidade de vida, e não apenas, ausência de doença. Dessa forma, dados relacionados aos fatores sociais, ambientais, econômicos e educacionais, que podem gerar enfermidades, tornam-se relevantes durante o contato dos profissionais de saúde com usuários do sistema ${ }^{(3)}$.

Este sistema possui importância no quadro sanitário brasileiro, não somente como estrutura de organização da área da saúde ou modelo teórico de atendimento à clientela, mas especialmente pela mudança que a sua instituição trouxe para o direcionamento das formas de pensar, conceber e realizar a assistência à saúde no país ${ }^{(4)}$.

A criação do SUS pode ser considerada uma "carta fundadora" de uma nova ordem social no âmbito da saúde. Ele é norteado por princípios doutrinários e por princípios organizativos $^{(1 ; 5)}$ baseados, por sua vez, nos princípios da universalidade e igualdade, e organizado sob as diretrizes da descentralização, atendimento integral e participação da comunidade ${ }^{(1)}$.

Universalidade, equidade e integralidade são os princípios doutrinários do SUS ${ }^{(1)}$.

A universalidade refere-se ao direito de todas as pessoas ao atendimento independente da cor, religião, local de moradia, situação de emprego ou renda, ou seja, a saúde é considerada direito de cidadania e dever dos governos municipal, estadual e federal(5).

O princípio de eqüidade reconhece que todo cidadão é igual perante o SUS que, por sua vez, deve considerar que cada grupo populacional vive de forma diferente, possui problemas específicos, com diferenças no modo de viver, de adoecer e de dispor de oportunidades para satisfazer suas necessidade de vida(5).

A integralidade preconiza que $o$ atendimento deve ser feito para a saúde do indivíduo e não só para sua doença. As ações de promoção, prevenção e reabilitação devem ser focadas no todo indivisível ${ }^{(5)}$.

Os princípios organizativos são definidos como: regionalização e hierarquização, descentralização, controle social, complementaridade do setor privado e resolutividade ${ }^{(5)}$.

Regionalização e hierarquização referem-se à forma de organização que deve permitir um conhecimento maior dos problemas de saúde da população de uma área delimitada, e favorecer ações de vigilância epidemiológica, sanitária, controle de vetores, educação em saúde, além das ações de atenção ambulatorial e hospitalar em todos os níveis de complexidade ${ }^{(5)}$.

A descentralização refere-se à redistribuição das responsabilidades às ações e aos serviços de saúde entre os vários níveis de governo ${ }^{(5)}$.

O controle social, também entendido como participação dos cidadãos, deve ser entendido como a garantia constitucional de que a população, por meio de entidades representativas, deverá participar do processo de formulação das políticas de saúde e do controle de sua execução, em todos os níveis, desde o federal até o local| ${ }^{(5)}$.

O princípio da resolutividade é definido como a exigência de que, quando um indivíduo busca atendimento ou quando surge um problema de impacto coletivo sobre a saúde, o serviço correspondente esteja capacitado para enfrentá-lo e resolvê-lo até o nível de sua complexidade ${ }^{(5)}$.

A resolutividade é avaliada a partir dos resultados obtidos no atendimento dos usuários ${ }^{(6)}$. Para um serviço ser resolutivo ele deve ser capaz de modificar positivamente a condição de saúde de um indivíduo, família ou de um grupo ${ }^{(7)}$, assim ela deve ocorrer considerando o modelo hierarquizado por níveis de atenção do $S U S^{(6)}$.

O nível primário é qualificado para realizar intervenções com enfoque preventivo, comunitário e coletivo, ou seja, os principais problemas que demandam serviços de saúde. Os casos que não puderem ser resolvidos neste nível são referenciados para o nível secundário, que se destina a desenvolver atividades assistenciais nas quatro especialidades médicas básicas: clínica médica, ginecologia e obstetrícia, pediatria e clínica cirúrgica, além de especialidades estratégicas, nas modalidades de atenção ambulatorial, internação, urgência e reabilitação. Já os casos mais complexos são destinados ao nível terciário, que se caracteriza pela maior capacidade resolutiva, nas modalidades de atendimento ambulatorial, internação e urgência ${ }^{(8)}$.

Supõe-se que, quanto maior a resolutividade de um serviço, mais ele está voltado e preparado para atender as necessidades de saúde da população, mesmo que isto signifique encaminhá-lo para outro serviço, para que ocorra a continuidade do atendimento. Para ser considerada resolutiva, a Unidade de Saúde deve ser capaz de atender à demandas e encaminhar os casos que necessitem de atendimento mais especializado para os outros níveis ${ }^{(6)}$.

Deste modo, compreende-se que a resolutividade deve se estender desde a consulta inicial do usuário no serviço de atenção primária à saúde até a solução de seu problema em outros níveis de atenção à saúde ${ }^{(6)}$. Mas, como os profissionais de saúde, que trabalham no SUS, têm percebido a resolutividade no cotidiano de suas ações?

A fim de responder essa indagação, o objetivo deste estudo é compreender o significado atribuído pelos profissionais da rede hierarquizada de saúde de Belo Horizonte-MG ao princípio da resolutividade nas ações cotidianas de saúde.

\section{METODOLOGIA}

Trata-se de um estudo de caso de caráter qualitativo, fundamentado na sociologia compreensiva. A utilização da 
abordagem qualitativa possibilita a compreensão das experiências vividas por uma população em estudo. A sociologia compreensiva busca entender o dado social, relativizando-o, pois este, fundamentado no aqui e agora, possui diversas interpretações e várias nuanças. Ela propõe a subjetividade como fundante de sentido e defende-a como constitutiva do social e inerente ao entendimento objetivo, e não se preocupa com os processos de quantificação, mas em explicar os meandros das relações sociais consideradas essência e resultado da atividade criadora, efetiva e racional ${ }^{(9)}$.

O universo das investigações qualitativas são o cotidiano e as experiências do senso comum, interpretadas e reinterpretadas pelos sujeitos que as vivenciam ${ }^{(9)}$, uma vez que a sociedade não é apenas um sistema mecânico de relações econômico-políticas ou sociais, mas um conjunto de relações interativas, composto por afetos, emoções, sensações que constituem, stricto sensu, o corpo social ${ }^{(10)}$ No cotidiano da existência das pessoas, as coisas não acontecem com a formalidade que a organização e o discurso dos teóricos querem que aconteçam, "o que permite as várias nuanças que ocorrem das macroestruturas às microestruturas, tentando relativizar as duas"(11).

O estudo de caso se apresenta como estratégia adequada, quando se trata de questões nas quais estão presentes fenômenos contemporâneos inseridos em contextos da vida real e podem ser complementados por outras investigações de caráter exploratório e descritivo. Ele é utilizado como estratégia de pesquisa nos estudos organizacionais e gerenciais, contribuindo, de forma inigualável, para a compreensão de fenômenos complexos, nos níveis individuais, organizacionais, sociais e políticos, permitindo a preservação das características significativas dos eventos da vida real ${ }^{(12)}$. Buscou-se, neste estudo, alcançar o nível individual, considerando-se as ações desenvolvidas pelos trabalhadores em suas atividades específicas e dos gerentes no desenvolvimento da função gerencial no contexto de algumas unidades que compõem o setor saúde de Belo Horizonte.

Assim, trinta e dois sujeitos, entre gestores e profissionais de saúde, pertencentes a cinco cenários de Belo Horizonte, foram os informantes desta pesquisa.

Os cenários foram um Centro de Referência em Saúde Mental (CERSAM), um Pronto Atendimento Médico (PAM), uma Unidade de Pronto-Atendimento (UPA) e duas Unidades Básicas de Saúde (UBS), sendo que uma delas está designada como Centro de Saúde (CS), para diferenciação dos respondentes.

Um dos critérios preliminares de escolha dos sujeitos foi ter no mínimo dez anos de trabalho em qualquer setor da rede, pois, se ainda não eram trabalhadores na implementação do SUS, em Belo Horizonte em 1993, estavam se graduando em um momento de transição.

Os profissionais foram convidados a participar da pesquisa em seu setor de trabalho podendo, inclusive, indicar outros colegas. Receberam a informação sobre o objetivo da pesquisa e sobre os procedimentos, ficando livres para aceitar ou se recusar a participar. Ao aceitarem, assinaram o Termo de Consentimento Livre e Esclarecido, conforme reza a Resolução 196/96. O anonimato foi assegurado.
Os profissionais foram identificados de acordo com as iniciais de sua categoria profissional: AE (auxiliar de enfermagem), TE (técnico de enfermagem), E (enfermeiro), M (médico), AS (assistente social), TO (terapeuta ocupacional) e G (gerente) no caso de gerentes, além do ACS (agente comunitário de saúde), seguidas da sigla do local onde atuam. Ressalta-se que o projeto foi aprovado pelo Comitê de Ética em Pesquisa da UFMG, sob o número ETIC 590/05.

Os dados primários foram coletados por meio de entrevistas semiestruturadas, com gestores e trabalhadores de saúde dos cenários do estudo. A entrevista individual foi fundamentada em um roteiro básico de perguntas, a partir das seguintes questões norteadoras: $\mathrm{O}$ que você compreende por integralidade, equidade e resolutividade em saúde? Como você pensa que esses princípios estão inseridos em sua prática cotidiana? Como você percebe o trabalho em equipe em seu setor? Como você vê a intersetorialidade em seu trabalho?

Para fins deste artigo, foram considerados apenas os dados sobre a resolutividade. Os dados primários foram tratados e analisados por meio da técnica de análise de conteúdo.

\section{RESULTADOS}

Da transcrição das entrevistas e após a organização e análise dos dados foram identificadas quatro categorias de análise que deram sentido ao significado atribuído pelos profissionais da rede hierarquizada de saúde de Belo Horizonte ao princípio da resolutividade: compreendendo a resolutividade, o foco da resolutividade, os dificultadores da resolutividade, e identificando a não-resolutividade.

\section{A. Compreendendo a resolutividade}

Essa categoria refere-se aos significados expressos pelos informantes sobre a resolutividade.

Percebe-se que os profissionais conceituam a resolutividade como a resolução de problemas dos pacientes, utilizando-se da consulta como um momento de escuta, de direcionamento, diálogo e de apoio.

É você tentar resolver da melhor maneira possível o problema do outro, escutando, ouvindo, é tentar resolver ali da melhor maneira possível, ou agendando uma consulta, ou conversando, dando uma palavra de apoio, ou tirando as dúvidas. E UBS

Acho que resolutividade é a gente pelo menos dar direção para um problema que aparece. E2 UBS

É função da enfermagem acolher os pacientes e solucionar as necessidades neles detectadas e por isso, esses profissionais desempenham um papel fundamental para a efetivação de um serviço de saúde com qualidade sendo, necessário que eles se posicionem de forma crítica frente às políticas de saúde, ajustando medidas administrativas às soluções de problemas de sua competência ${ }^{(13)}$.

Os profissionais de saúde compreendem, também, que um serviço resolutivo é aquele capaz de encaminhar os pacientes 
quando eles não conseguem atender uma determinada demanda. Porém, é ressaltado que para haver resolutividade, o sistema de referência e contra referência precisa funcionar de forma apropriada.

Acho que é quando você consegue ver o caso andando, sabe? Quando você por exemplo, é...um exemplo... você tem um caso aqui do CERSAM e você encaminha pra UPA e UPA te dá a contra referência de uma maneira segura, de uma maneira com relatório que te mostra que não tinha nada daquilo, por exemplo, era uma suspeita de uma infecção não tem, então, o quadro ta limpo, era só uma psicose mesmo. TO CERSAM

O sistema de referência e contra referência deve realizar uma articulação com os três níveis de atenção. Ele é considerado um dos pontos mais importantes para viabilizar a implantação do SUS ${ }^{(14)}$.

Quando o usuário tem uma demanda que o serviço não consegue atender, ele deve ser encaminhado para outro de referência, que atenda um maior grau de complexidade. Após atender a demanda do paciente, a unidade de referência deve contra referenciar o usuário novamente para o de menor grau ${ }^{(15)}$. Desta maneira os profissionais percebem que, de alguma forma, as demandas dos pacientes sendo atendidas, o serviço estaria sendo resolutivo.

Constata-se também que profissionais consideram que nem sempre os pacientes saem com a resposta que desejam, uma vez que a demanda nem sempre é tratada no serviço onde procuram o atendimento. Afirmam que embora isso aconteça, o serviço é resolutivo no que corresponde ao seu nível de atenção, embora para a população seja o inverso.

O paciente não sai sem uma resposta, mas não quer dizer que seja uma resposta que o paciente quer, porque eu fico com a responsabilidade de dizer não. AS UPA

Aqui a gente tem uma triagem, assim se o paciente é classificado como azul ele já é encaminhado para o centro de saúde. A função nossa não é resolver o que o paciente quer. Às vezes é um caso que não tem necessidade de ficar na UPA, pode resolver no centro de saúde. AS UPA

Porém, na visão dos gerentes, para ser resolutivo um serviço precisa encaminhar pouco e ser capaz de corresponder às expectativas dos usuários. Explicita-se que a satisfação e a capacidade de assistir são os resultados em um sistema produtivo.

É oferecer a resposta de acordo com a necessidade e expectativa do usuário. G UPA

É a gente ser resolutivo. Isso num âmbito maior. No âmbito da saúde é a gente encaminhar pouco. A gente procurar resolver os problemas de saúde todos aqui dentro da unidade. G UBS

Aqui no dia-a-dia a gente tem a prática de estar procurando resolver tudo aqui mesmo, buscando até ajuda em outros setores para a gente tentar manter o paciente aqui mesmo, tentar resolver o problema dele aqui dentro do centro de saúde. G UBS

No processo de trabalho, o gerente deve adequar determinados mecanismos próprios da unidade, que propiciem o desenvolvimento da execução da prática gerencial, visando à garantia dos princípios do SUS. Ele elabora pensamentos e a sua idealização se projeta no modo como organiza o trabalho para produção de bens e serviços, e na direção do atendimento das necessidades geradas por uma determinada sociedade ${ }^{(16)}$.

Porém, constata-se que a compreensão dos gerentes sobre resolutividade, diverge da de outros membros da equipe de saúde. Tal realidade sugere que a garantia dos princípios do SUS tem dependido de quem acolhe cada paciente.

\section{B. $O$ foco da resolutividade}

Os serviços de saúde só têm conseguido ser resolutivos no que se refere à queixa principal dos pacientes e desde que focada no tipo de atendimento prestado na unidade. Mas, cabe ressaltar que nem todos os pacientes têm conseguido ser atendidos e ter suas demandas supridas no mesmo dia que procuram atendimento.

Os profissionais conseguem visualizar, também, que ora a demanda não é específica para aquele nível de atendimento, ora não são problemas de saúde física e, como conseqüência o atendimento tem que ser priorizado ou organizado após a escuta dos sintomas.

Às vezes o paciente apresenta uma demanda que não vai ser resolvida aqui na UPA, e sim no centro de saúde ou hospital Odilon Berens ou João XXIII. AS UPA

[...] muitas queixas da comunidade são queixas sociais que não é problema da UPA [...] mas esse paciente é referenciado para o posto para atendimento psicológico, acompanhamento. E2 UPA

[...] pela manhã é distribuída uma senha para quem chega, então você vai chamando por ordem e ouvindo cada um, ali você vai vendo a prioridade, quem tem realmente que esta passando no dia, você marca pro dia,o agudo. E UBS

O fato do processo de trabalho em saúde ainda estar focado em ações curativas, tem desencadeado a existência de filas de usuários, desde a madrugada, em busca de "uma ficha" para atendimento médico. Nesse casos, parece haver, a importação da lógica dos serviços de emergência e de urgência ao trabalho da atenção primária à saúde que deveria buscar integrar ações curativas com as de promoção e de prevenção à saúde ${ }^{(17)}$.

No entanto, quando o foco é respeitado, ou seja, quando a queixa do paciente é relacionada com o foco de atendimento da unidade, os profissionais entendem que o atendimento é resolutivo. 
Na urgência nós temos uma resolutividade imediata, consegue resolver o problema de forma imediata. E UPA

É resoluto também na consulta, o paciente que precisa de atendimento rápido, como uma cólica renal E2

Mas acho que a resolutividade aqui por exemplo é agente atender um paciente em crise, a gente tirar esse paciente da crise, né? E fazer um projeto de reinserção social. Isso eu acho que é um atendimento com resolutividade. M CERSAM

\section{Dificultadores da resolutividade}

Algumas "barreiras" são descritas como dificultadores para a resolutividade, como informações deficientes, demandas elevadas, déficits de infra-estrutura e a dependência de sistemas de contra-referência.

Os profissionais de saúde afirmam que os pacientes desconhecem as finalidades dos níveis de atenção à saúde, por não existir informações adequadas sobre as mesmas, e isso faz com que procurem atendimentos, que poderiam ser realizados em unidades básicas, em serviços de maior complexidade.

A procura acontece porque não tem uma propaganda falando da finalidade da UPA e do posto. As pessoas não sabem o que é UPA. E2 UPA

Muitas vezes a procura é pela consulta e não pelo atendimento de urgência. E2 UPA

Essa realidade ocasiona um aumento da demanda em alguns serviços, o que dificulta a resolutividade.

Os pacientes sentem alguma coisa e procuram o $P A$, então a demanda é muito grande. E2 UPA

[...] a unidade é um lugar onde todo esse pessoal recorre para resolver o que precisa. ACS UBS

Tipo assim, as coisas são muito pouco resolutivas, sabe. Eu não sei se a demanda é muito grande para os profissionais estarem atendendo tudo a tempo e a hora. TE UPA

Apesar de amparado pelo SUS, sistema único de saúde, não temos condição de atender toda esta demanda. AS UPA

Não dá para resolver tudo aqui porque a equipe é uma só. Então fica difícil atender a população inteira da área de abrangência da comunidade. O UBS

Em um estudo realizado em uma unidade de emergência de pacientes adultos, de um hospital geral de Pernambuco, identificou-se que $74,5 \%$ dos atendimentos realizados no serviço eram por queixas típicas da atenção básica, não se caracterizando, portanto, como urgência. Essa realidade ocasiona um aumento na demanda e prejudica a assistência aos casos graves e agudos, pois acarreta acúmulo de tarefas, contribuindo também para o aumento dos custos de atendimento e sobrecarga para os profissionais da equipe de saúde ${ }^{(18)}$.

Constata-se deste modo, que usuários procuram os serviços hospitalares de urgência como uma das alternativas de acesso, pois entendem que eles reúnem um somatório de recursos, como consultas, remédios, procedimentos de enfermagem, exames laboratoriais e internações, que os tornam mais resolutivos ${ }^{(19)}$.

A infra-estrutura das unidades de atendimento também é percebida pelos profissionais como ponto dificultador para a resolução das demandas, por gerar um aumento no tempo de espera pelo atendimento.

Percebe-se que não há um consenso sobre o tempo máximo que os pacientes podem permanecer na unidade de pronto-atendimento, aguardando a resolução de seus problemas, e que a demora do atendimento acaba gerando reclamações.

Temos um problema sério aqui, é do paciente ficar por 15 dias e sendo que ele deveria permanecer no máximo 16hs, não é? E UPA

Aqui a proposta é para o paciente ficar $24 \mathrm{~h}$ e aí ele fica mais pela própria estrutura que nós não conseguimos atender nesse prazo. AS UPA

Um atendente chega e fala para ele avisar na portaria que o atendimento está demorando de 3 a 4 horas para as pessoas não reclamarem se quiserem esperar. TE4 UPA

Além desses fatores intervenientes, também foi identificado que existem dificuldades relacionadas a encaminhamentos e transferências, e por este motivo a resolutividade não é alcançada.

Mas o que é fora, a gente tem dificuldade de estar resolvendo, como por exemplo a consulta especializada, a parte especializada a gente tem dificuldade: canal, periodontia, endodontia, cirurgia. Encaminhamento nosso fica aí anos e anos esperando para ser chamado." O UBS

Tem coisas que a gente não consegue vaga, por exemplo: necrose, ferida, sabe, essas coisas são super difíceis pra nós conserguirmos vaga [...] Não sei porquê, mas os hospitais do SUS não estão querendo trabalhar para o SUS. E3 UPA

Essas dificuldades têm um impacto direto na resolutividade, pois esta envolve aspectos relativos à demanda, à satisfação do cliente, às tecnologias dos serviços de saúde, à existência de um sistema de referência preestabelecido, à acessibilidade dos serviços, à formação dos recursos humanos, às necessidades de saúde da população, à adesão ao tratamento, aos aspectos culturais e sócio-econômicos da clientela, entre outros ${ }^{(6)}$.

Sabendo que nenhuma organização reúne a totalidade dos recursos e competência necessária para a solução dos problemas de saúde de uma população, e que existem barreiras de acesso entre os diversos níveis de atenção à saúde, para que sejam dadas respostas às necessidades de saúde dos usuários é necessário compartilhar experiências pessoais com a comunidade, com os profissionais de saúde da equipe local e as 
autoridades competentes, para a integração de serviços, em favor de um interesse comum: a integralidade em saúde ${ }^{(17)}$.

\section{Identificando a não resolutividade}

Os profissionais referem alguns indicadores da não resolutividade, tais como a incidência elevada de retorno e o fato dos serviços ainda não conseguirem focar em seu nível de atuação.

Eu acho que... a gente vê que não é tão resolutivo quando você vê um caso simples voltando, é quando você vê um caso que foi encaminhado indevidamente pro CERSAM, eu acho que não fica muito resolutivo. Um bate e volta na rede, fica... eu acho que não é tão resolutivo não. TO CERSAM

A partir do momento que você conseguir tirar o PSF do papel e colocar ele realmente na prática isso vai ajudar e muito. Porque você atende um paciente hoje com um caso agudo e amanhã ele retorna. Por quê? Porque você não está não está trabalhando com aquela... como posso falar? A prevenção, né? E3 UBS

Percebe-se na fala, de alguns dos entrevistados, uma preocupação na avaliação dos motivos do retorno do paciente, já que eles podem estar relacionados com o atendimento ou encaminhamentos indevidos.

Os níveis de atenção do SUS possuem complexidades crescentes, e para que esse sistema seja resolutivo os casos só deverão ser encaminhados para um nível de complexidade maior quando forem esgotadas todas as possibilidades de atendimento do nível primário. Nota-se, que os profissionais colocam que o principal problema é a pouca resolutividade dos níveis cuja função é de prevenção, o que tem gerado encaminhamentos indevidos e retornos constantes dos pacientes.

A demanda excedente e/ou a falta de resolutividade de alguns atendimentos prestados, em diferentes pontos do sistema, faz com que usuários tenham que procurar outros serviços ou submeter-se a mais de um atendimento para obter a satisfação de suas necessidades ${ }^{(19)}$.

O modelo assistencial do sistema de saúde brasileiro deveria funcionar como uma pirâmide, com fluxos ascendentes e descendentes de usuários. Na base desta pirâmide estariam as unidades de saúde, ou seja, a atenção primária visando atender os grupos populacionais e funcionando como uma "porta de entrada" para os níveis superiores de maior complexidade tecnológicas. Porém, a ineficiência do atendimento primário à saúde (unidades básicas), torna os prontos socorros e hospitais a porta de entrada para a assistência à saúde da população, além da centralização deste modelo no atendimento médico, que possui pouca ou nenhuma prática de prevenção de doenças e promoção de saúde ${ }^{(20)}$.

Deste modo, percebe-se que rede básica, pode inicialmente contribuir ou não para uma melhor performance da assistência especializada. Pois uma maior resolutividade da assistência prestada no nível primário pode reduzir a demanda por consultas especializadas e exames, especialmente os de maior complexidade, reservando os recursos públicos para garantir os procedimentos realmente necessários ${ }^{(20)}$.
Fazer encaminhamentos para a rede secundária e terciária sem haver esgotado as possibilidades diagnósticas na rede básica, revela um modo de operar o trabalho em saúde, em que falta solidariedade com o serviço e responsabilização no cuidado ao usuário ${ }^{(20)}$.

A resolutividade na rede básica deve estar ligada não somente ao recurso instrumental e ao conhecimento técnico dos profissionais, mas também à ação acolhedora, ao vínculo que se estabelece com o usuário e ao significado que se dá na relação profissional/usuário ${ }^{(20)}$.

\section{CONSIDERAÇÕES FINAIS}

Ao analisar o significado atribuído pelos profissionais da rede hierarquizada de saúde de Belo Horizonte - MG ao princípio da resolutividade nas ações cotidianas de saúde, identificou-se que existe a preocupação da resolutividade como a resolução de problemas dos pacientes, utilizando-se a consulta como um momento de escuta, de direcionamento, diálogo e de apoio; e a compreensão de que um serviço resolutivo é aquele capaz de encaminhar os pacientes quando eles não conseguem atender uma determinada demanda.

No entanto, os profissionais ressaltam que, para haver resolutividade, o sistema de referência e contrarreferência precisa funcionar de forma apropriada e que os profissionais consideram que nem sempre os pacientes saem com a resposta que desejam, mas para eles isso não representa que não houve resolutividade, embora para a população seja o inverso, e para os gerentes também, uma vez que para esses, um serviço resolutivo precisa encaminhar pouco e ser capaz de corresponder às expectativas dos usuários.

Outro aspecto levantado é que os serviços de saúde só têm conseguido ser resolutivos no que se refere à queixa principal dos pacientes e, isso só tem sido alcançado, quando essa queixa é centrada no tipo de atendimento prestado na unidade.

Tal realidade tem favorecido a não resolutividade, uma vez que as demandas dos pacientes não têm sido supridas.

Constatou-se que alguns fatores têm contribuído para a não resolutividade como informações deficientes sobre a finalidade de cada um dos níveis de atenção à saúde, que por sua vez geram demandas elevadas nos níveis de maior complexidade, já que a população compreende que nesses serviços suas queixas serão resolvidas.

Déficits de infraestrutura e a dependência de sistemas de contrarreferência também foram apontados como fatores que dificultam a resolutividade.

Diante do exposto, percebe-se que apesar do serviço, no qual as pessoas buscam atendimento, ter a missão de resolver os problemas de acordo com seu nível de complexidade, isso nem sempre tem ocorrido, havendo a necessidade de uma reorganização da infraestrutura disponível, capacitação de recursos humanos, educação da população e divulgação efetiva da rede hierarquizada por parte dos órgãos competentes.

Além disso, constatou-se divergências de opiniões entre os profissionais ouvidos sobre o que é resolutividade, fato que pode comprometer a concretização desse princípio organizativo do SUS. 


\section{REFERÊNCIAS}

1. Brasil. Ministério da Saúde. Secretaria-Executiva. Qualisus - Política de qualificação da atenção à saúde. Brasília, 2004.

2. Gusmao-Filho FAR. Análise de implantação da Política de Qualificação da Atenção à Saúde do Sistema Único de Saúde - Política Qualisus - em três hospitais do município do Recife. Recife. Tese [Doutorado em Saúde Pública]- Centro de Pesquisas Aggeu Magalhães. Fundação Oswaldo Cruz, 2008.

3. Almeida ES, Castro CGJ, Vieira AL. Distritos Sanitários: Concepção e Organização, volume . São Paulo: Faculdade de Saúde Pública da Universidade de São Paulo, 1998. v.1 (Série Saúde \& Cidadania)

4. Oliveira DC, Gomes AMT, Sá CP, Acioli S. A atenção pública à saúde e a contituição simbólica do Sistema único de Saúde: representações socioprofissionais. Psicol Teor Prat 2007;9(2):26-46.

5. Brasil. Lei $n .{ }^{\circ} 8.080$, de 19 de setembro de 1990. Dispõe sobre as condições para a promoção, proteção e recuperação de saúde, a organização e o funcionamento dos serviços correspondentes e dá outras providências. Diário Oficial da União 19 set 1990.

6. Turrini RNT, Lebrão ML, Cesar CLG. Resolutividade dos serviços de saúde por inquérito domiciliar: percepção do usuário. Caderno de saúde pública 2008;24(3):663-75.

7. Degani VCA. A resolutividade dos problemas de saúde: opinião de usuários em uma unidade básica de saúde. 2002. 197f. Dissertação (Mestrado em Enfermagem) - Escola de Enfermagem, Universidade Federal do Rio Grande do Sul, Porto Alegre, 2002.

8. Pinho IC, Siqueira JCBA, Pinho LMO. As percepções do enfermeiro acerca da integralidade da assistência. Rev Eletrônica Enferm 2006;8(1):42-51.

9. Minayo MCS. O desafio do conhecimento: pesquisa qualitativa em saúde. 9. ed. São Paulo: Hucitec; 2006.
10. Maffesoli M. No fundo das aparências. Petrópolis: Vozes; 1996.

11. Penna CMM. Ser saudável no quotidiano da favela. Pelotas: Ed. Universitária/UFPEL; 1997.

12. Yin RK. Estudo de caso: planejamento e métodos. 3. ed. Porto Alegre: Bookman; 2005.

13. Correia VS, Servo MLS. Supervisão da Enfermeira em Unidades Básicas de Saúde. Rev Bras Enferm 2006;11(4):527-31.

14. Juliani CMCM, CIAMPONE MHT. Organização do sistema de referência e contra-referência no contexto do Sistema Único de Saúde: a percepção de Enfermeiros. Rev Esc Enferm USP 1999;33(4):323-33.

15. Brasil. Ministério da Saúde. Fundo Nacional de Saúde. Gestão Financeira do Sistema Único de Saúde: manual básico. 3.ed. Brasília; 2003.

16. Passos JP, Ciosak SI. A concepção dos enfermeiros no processo gerencial em Unidade Básica de Saúde. Rev Esc Enferm USP 2006;40(4):464-68.

17. Viegas SMF, Penna CMM. Integralidade e saúde da população: a construção da estratégia de saúde da família em distrito brasileiro. In: Pinheiro R, Mattos RA. Ateliê do cuidado: trabalhos completos / VII Seminário do Projeto Integralidade: saberes e práticas no cotidiano das instituições de saúde. Rio de Janeiro: ABRASCO; 2008.

18. Furtado BMASM, Araújo JLC, Cavalcanti P. O perfil da emergência do hospital da restauração: uma análise dos possíveis impactos após a municipalização dos serviços de saúde. Rev Bras Epidemiol 2004;7(3):279-89.

19. Marques GQ, Lima MADS. Demandas de usuários a um serviço de pronto atendimento e seu acolhimento ao sistema de saúde. Rev Latino-Am Enferm 2007;5(1):13-9.

20. Silva TR. Saúde Coletiva e Atividade Física: Conceitos e Aplicações Dirigidos à Graduação em Educação Física. Campinas: IPES Editorial; 2007. 